\title{
LA ÚLTIMA JURISPRUDENCIA DE LA CORTE COSTITUZIONALE ITALIANA EN MATERIA DE SECRETOS DE ESTADO
}

\author{
SUSANA SÁNCHEZ FERRO \\ Profesora Contratada Doctora \\ Universidad Autónoma de Madrid
}
SUMARIO
I. Introducción.
II. El contexto legislativo.
III. La sentencia de la Corte Costituzionale núme- ro 206/2009, de 8 de abril, sobre el secreto de Estado y el programa de extraordinary rendi- tions.
IV. La sentencia de la Corte Costituzionale núme- ro 40/2012, de 29 de febrero.
V. Análisis final.

\section{INTRODUCCIÓN}

La Corte Costituzionale italiana ha revisado su jurisprudencia en materia de secretos de Estado y derecho a la prueba en el proceso penal en dos sentencias recientes, la última publicada en febrero de 2012, resolviendo en ambas diversos conflictos de atribuciones entre el Ejecutivo y el poder judicial y estando en el centro de la confrontación el problema de la fiscalización de los secretos de Estado.

En dichas sentencias la Corte Costituzionale reproduce en parte la jurisprudencia de años anteriores sobre la materia, pero sobre todo clarifica su papel en el control del secreto de Estado, cosa que no había hecho hasta ahora. Como veremos, la Corte Costituzionale se muestra mucho más deferente hacia el Ejecutivo de lo que se mostró el Tribunal Supremo español en la famosa Sentencia de los «Papeles del Cesid» del año $1997^{1}$. La Corte realiza,

1 En realidad, más que hablar de la Sentencia de los «Papeles del Cesid» habría que hablar de las sentencias de los «Papeles del Cesid», pues fueron varias las dictadas por el Tribunal Supremo en este caso, todas de 4 de abril de 1997. Las sentencias eran prácticamente idénticas en lo que se refiere a su fundamentación ju- 
además, en estas sentencias, una interpretación novedosa sobre el derecho de defensa del imputado y el secreto de Estado. Se basa en una interpretación, según algún autor, aditiva $^{2}$, del nuevo artículo 41.1 de la Ley de 3 de agosto de 2007 (ley 124/2007, sobre el Sistema de Información para la Seguridad de la República y la Nueva Disciplina del Secreto de Estado), que vino a sustituir a la vieja Ley 801 de 1977. Dicha ley ha sido parcialmente reformada a raíz de la Sentencia 40/2012 por la Ley 133/2012, de 7 de agosto.Aunque la jurisprudencia de la Corte ha supuesto un avance respecto a sus primeras sentencias sobre la materia, en nuestra opinión la Corte es todavía demasiado deferente hacia el Ejecutivo, como se verá a continuación.

\section{EL CONTEXTO LEGISLATIVO}

Antes de entrar en la fundamentación de las sentencias es preciso aclarar, aunque sea someramente, cuál es la regulación legal del secreto de Estado en Italia.

La Ley 801/1977, de 24 de octubre, disponía en su artículo 12 que serían secretos de Estado los actos, documentos, noticias, actividades o cualquier otra cosa cuya difusión fuera idónea para producir daño a la integridad del Estado democrático (en relación también con los tratados internacionales), a la defensa de las instituciones creadas por la Constitución como fundamento del Estado, al libre ejercicio de las funciones de los órganos constitucionales, a la independencia del Estado, o a la preparación y defensa militar del Estado. Añadía este artículo que en ningún caso podían constituir secretos de Estado los hechos destructivos del orden constitucional (fatti eversivi dell'ordine costituzionale) siguiendo en esto lo establecido en la Sentencia de la Corte Costituzionale número 86 de 24 de mayo de 1977. La nueva ley 124/2007 elimina de la definición del secreto de Estado la referencia al libre ejercicio de las funciones de los órganos constitucionales (artículo 39.1). Por otro lado, el artículo 39.11 excluye de la protección del secreto de Estado los actos de terrorismo, subversión y otros crímenes igualmente graves.

En Italia se distingue entre el atto di apposizione del secreto y el atto di opposizione. El atto di apposizione es el acto de individuación del secreto de Estado. La nueva Ley 124/2007 determina que es el Primer Ministro italiano el que especificará por Decreto los criterios para individualizar los casos en que puede declararse un secreto de Estado (art. 39.5).

El atto di opposizione implica la alegación de la existencia de un secreto de Estadofrente a los requerimientos de las autoridades competentes que quisieran incorporar dicho material a una causa abierta. De acuerdo con el artículo 202 del Código di Procedura Penale de 1988, vigente cuando se plantearon los tres primeros conflictos de atribuciones que resolvió la Corte en la Sentencia 106/2009, los empleados públicos, funcionarios o cualquiera que trabajase para el Estado, tenían la obligación de no prestar testimonio cuando se tratase de informaciones cubiertas por el secreto de Estado. Si el testigo

rídica esencial por lo que tomaremos sólo una como referencia cuando citemos las mismas, la núm. 726/1996, de 4 de abril de 1997, dictada por la Sala Tercera del Tribunal Supremo.

2 FANCHIOTTI, Vittorio: Il gusto (amaro) del segreto, en Giurisprudenza Costituzionale, 2009 (vol. 2), p. 1034. 
oponía el secreto de Estado para no declarar, el juez informaría al Primer Ministro para que confirmase (o no) la existencia del secreto de Estado (atto di conferma). El proyecto de Código procesal penal de 1988 exigía al Primer Ministro que indicara las razones esenciales en caso de confirmación del secreto de Estado, pero finalmente se consideró que era mejor eliminar esta exigencia para seguir con el modelo que había establecido la Ley n. ${ }^{\circ} 801$ de 1977, que primaba la relación Gobierno-Parlamento sobre la de JuecesGobierno. El Código procesal penal exigía únicamente que el Primer Ministro diera esas explicaciones al comité parlamentario de control de los secretos de Estado. Este comité parlamentario de control era, según el modelo de la ley n. ${ }^{\circ} 801 / 1977$, bicameral y estaba formado por cuatro diputados y cuatro senadores, nombrados por los Presidentes de ambas Cámaras sobre la base del criterio de proporcionalidad ${ }^{3}$. Si los miembros de esta comisión, por mayoría absoluta de sus miembros, entendían que la oposición del secreto no tenía fundamento, el asunto se llevaba al Pleno de ambas Cámaras para que en ellas se desarrollasen las valoraciones políticas oportunas. Se entendía que éste era el mecanismo que preservaba mejor el equilibrio de poderes ya que la sede principal para evaluar las decisiones de alta política del Gobierno debía ser el Parlamento ${ }^{4}$.

En el caso de secretos ilegales, que concernieran a hechos, informaciones o documentos relacionados con delitos que tuvieran por objeto la destrucción del orden constitucional (fatti eversivi dell'ordine costituzionale), el testigo, por mor de lo dispuesto en el artículo 204 C.p.p., no podría recurrir a la oposición del secreto de Estado para no declarar. En principio sería el juez quien determinase si el delito que se estaba juzgando y al que afectaba el contenido del secreto era de esta clase de delitos.

En fin, el apartado tercero del artículo 202 (C.p.p.) disponía que cuando el secreto fuera confirmado y la prueba fuera esencial para la resolución del proceso, el juez declararía que no se podía proseguir con el mismo por la existencia de un secreto de Estado. Es decir, que sólo cuando no se pudiera resolver sin esa prueba concreta (sea en el sentido de absolver al reo o de condenarlo) se paralizaría el proceso penal. Parece que el juez podría buscar esa información por otras vías.

Por lo demás, el artículo 202 C.p.p. expresamente señalaba que si el Primer Ministro no respondía en el plazo de sesenta días desde que recibía la solicitud de confirmación del secreto por el juez, el testigo sería obligado a declarar.

En cuanto a la prueba documental, el código procesal penal disponía un mecanismo paralelo al de la prueba testifical. El artículo que regulaba la oposición del secreto de Estado en estos casos era el artículo 256 C.p.p. Los sujetos legitimados para oponer el secreto eran los mismos que los legitimados para hacerlo en la prueba testifical. Cuando el Primer Ministro no confirmase el secreto, el juez podría proceder al secuestro del documento pero no se podría perseguir al que hubiera opuesto el secreto sin fundamento por delito de falso testimonios.

3 LABRIOLA: «Segreto di Stato» en Enciclopedia del Diritto, tomo XLI, Giuffrè, Varese, 1989, pp. 10281036, p. 1034 .

4 GREVI: «Segreto di Stato e processo penale», en Il segreto nella realtà giuridica italiana. Atti del ConvegnoNazionale, CEDAM, Padova, 1983, pp. 225-250, p. 247.

5 FIORAVANTI, Laura: «Il segreto di Stato nel nuovo Codice di Procedura Penale», en Politica del Diritto, núm. 2, 1989, pp. 273-318, pp. 299 y 300. 
La nueva Ley 124/2007 vino a modificar en algunos puntos esta regulación y dar nueva redacción a los artículos 202 y 204 del Código procesal penal italiano, y al artículo 66 de las normas transitorias del Código procesal penal. Los artículos de la ley que modifican estos preceptos son los artículos 40 y 41. El artículo 40 hace referencia a la prueba de testigos e impide a los funcionarios públicos, empleados públicos y encargados de un servicio público declarar sobre hechos cubiertos por el secreto de Estado (dando redacción al nuevo artículo 202.1 C.p.p.). El artículo 41 señala, de manera genérica (sin hacer referencia a la prueba de testigos), y ahí está la diferencia con el régimen anterior que los funcionarios públicos, los empleados públicos y los encargados de un servicio público no pueden hacer referencia a hechos cubiertos por el Secreto de Estado. Cuando se opone el secreto de Estado, el juez informa al Primer Ministro para ver si confirma la existencia del secreto, suspendiendo cualquier iniciativa para adquirir el material secreto. Los artículos 40.5 y 41.5 de la ley exigen, como novedad, expresamente al Primer Ministro que el acto de confirmación del secreto ante el juez incluya una motivación (antes se le exigía sólo que motivara la confirmación ante el Comité parlamentario). Esto podría ser un elemento importante en el control del secreto de Estado.

Por primera vez la Ley introduce una nueva garantía frente al abuso, señalando que el hecho de que los documentos o la información estén clasificados no es una razón para denegar al juez el acceso a la información. El Primer Ministro deberá analizar si concurre un daño actual para la seguridad del Estado si se hiciera pública la información. La ley permite que incluso en ausencia de previa clasificación de la información, el Primer Ministro pueda confirmar que se trata de un secreto de Estado si ha habido oposición del secreto en el juicio (art. 204.1 ter C.p.p. y art. 40 de la Ley n.124/2007). Si el Primer Ministro confirma el secreto, el juez no puede adquirir el material secreto, ni utilizarlo como prueba (si ya estaba en su poder), ni directa ni indirectamente. El juez podrá proceder con la causa recurriendo, si puede, a elementos autónomos e independientes de aquéllos que fueron declarados secreto de Estado. Si en los treinta días siguientes a la notificación de la oposición del secreto al Primer Ministro éste no confirma el mismo, el juez o tribunal puede acceder a la información (art. 202.4 C.p.p.).

La nueva ley menciona expresamente la posibilidad de iniciar un conflicto de atribuciones entre los jueces y el Primer Ministro ante la Corte Costituzionale y sobre todo, señala que en ningún caso el secreto de Estado será oponible a la Corte, que adoptará las garantías necesarias para el mantenimiento del secreto (arts. 40.8 y 41.8 de la Ley n $\left.{ }^{\circ} 124 / 2007\right)$. Además, el conflicto no terminará declarando a quién pertenece la competencia sino con un pronunciamiento sobre la subsistencia o insubsistencia del secreto. Este nuevo Régimen legal parecía abrir una puerta para que la Corte asumiera un nuevo papel en el control de los secretos de Estado, cuestión a la que da respuesta la Sentencia de la Corte 106/2009. En fin, el artículo 40 de la ley señala, en relación con el artículo 39, que se excluye de la protección del secreto de Estado los actos de terrorismo, subversión y otros crímenes igualmente graves. El Primer Ministro podrá, además, confirmar el secreto si cree que el acto, la información o el documento cubierto por el secreto de Estado que se requiere no atañe al delito que está siendo juzgado. Este apartado de la ley ha sido criticado porque es el juez ordinario el que debería hacer ese tipo de consideración, ya que a él compete la determinación de la relevancia de la prueba para el proceso. 


\section{LA SENTENCIA DE LA CORTE COSTITUZIONALE NÚMERO 106/2009, DE 8 DE ABRIL, SOBRE EL SECRETO DE ESTADO Y EL PROGRAMA DE EXTRAORDINARY RENDITIONS}

\subsection{El planteamiento de los conflictos de atribuciones}

La Sentencia 106/2009 trajo causa del conocido como caso Abu Omar. Esta sentencia resolvió nada menos que cinco conflictos de atribuciones acumulados.

Usama Mustafa Hassan Nasr, Imán conocido como Abu Omar, fue secuestrado en Milán y posteriormente entregado a Egipto supuestamente por Agentes del SISMI (entonces uno de los dos servicios de inteligencia italianos) y por agentes de la CIA. Varios agentes de la CIA fueron condenados por este hecho por los tribunales italianos que, sin embargo, no pudieron condenar a los agentes del SISMI en primera instancia debido a que las pruebas que podrían haber incriminando a éstos, y que fueron declaradas secretas, no pudieron ser incorporadas a juicio.

El secuestro y entrega de Abu Omar a Egipto fue parte del programa conocido como extraordinary renditions practicado durante la época del Presidente Bush bajo la llamada guerra contra el terrorismo desatada tras el 11-S. Abu Omar alegó que en Egipto había sido torturado y había sufrido tratos inhumanos y degradantes.

El Fiscal de Milán (las tareas de la fiscalía las desempeñan jueces) comenzó a indagar sobre el caso y finalmente, en 2006, decidió pedir al Juez de Instrucción que abriera la instrucción del caso, petición a la que el Juez de Instrucción accedió. El Primer Ministro italiano planteó conflicto de atribuciones ante la Corte Costituzionale frente al Fiscal y al Juez de Instrucción por entender que habían basado sus actuaciones en informaciones recibidas que estarían cubiertas por el secreto de Estado. El Fiscal y el Juez de Instrucción plantearon a su vez sendos conflictos de atribuciones frente al Primer Ministro. Todos estos conflictos de atribuciones se plantearon antes de que el Parlamento aprobara la nueva ley 124/2007 sobre el Sistema de Información para la Seguridad de la República y la Nueva Disciplina del Secreto de Estado, esto es, bajo la vigencia de la Ley 801/1977.

El Tribunal de Milán ante el que se iba a desarrollar la fase oral del juicio, en vez de esperar a que se resolvieran estos conflictos de atribuciones, que podían tener incidencia en el caso, decidió abrir la fase oral del juicio en el año 2008, hecho que provocó que el Primer Ministro italiano elevase un nuevo conflicto de atribuciones ante la Corte Costituzionale (en este último conflicto la legislación relevante aplicable al caso era ya la de la Ley 124/2007).

El primer conflicto planteado por el Primer Ministro italiano deriva de los siguientes hechos. El cinco de julio de 2006 el Fiscal procedió al registro y secuestro de documentación en la sede del SISMI, en particular de un dossier de documentos conocidos como D-19, sin que ninguno de los funcionarios del SISMI presentes en el acto se opusiera a dicha actuación. El 31 de octubre de 2006, sin embargo, el Director del SISMI envió el dossier D-19 al Fiscal, pero en esta ocasión con determinadas partes del mismo tachadas por entender que dichos pasajes constituían secretos de Estado, puesto que revelaban nombres de agentes extranjeros, siglas secretas relativas al servicio secreto y relaciones entre el servicio de inteligencia italiano y los servicios de inteligencia extran- 
jeros. El Fiscal sin embargo, utilizó el dossier sin tachaduras (completo) como base de posteriores indagaciones y de su decisión de reenviar a juicio el caso y transmitió todo el dossier al Parlamento Europeo, documentación que fue publicada en internet. Por otro lado, el Fiscal llevó a cabo ciertos interrogatorios que versaron sobre información que el Primer Ministro consideró cubierta por el secreto de Estado.

El Primer Ministro, con fundamento en sus competencias en materia de declaración y confirmación del secreto de Estado, solicitó de la Corte que anulase las investigaciones basadas en el dossier D-19 completo y que anulase también la petición del Fiscal de reenvío a juicio en cuanto a que estaba basada en dicha documentación secreta y en la información recabada a través de las otras actuaciones realizadas por el Fiscal cubiertas por el secreto.

En el segundo conflicto de atribuciones planteado, éste frente al juez de instrucción, el Primer Ministro exigía igualmente la anulación de la decisión del juez de instrucción de llevar a juicio a los imputados y fijar la apertura de la fase oral (que se realizaría ante el Tribunal de Milán) por sustentarse la decisión, según el Primer Ministro, en la información que debería haberse considerado como secreta.

El Fiscal planteó a su vez conflicto de atribuciones ante la Corte Costituzionale por considerar que el Primer Ministro no podía declarar secretos los hechos e informaciones referentes a la planificación, modalidad organizativa y ejecutiva del secuestro de persona por constituir el mismo un hecho destructivo del orden constitucional y entrar en la categoría de «fatti eversivi dell'ordine costituzionale», sobre los que se prohíbe el secreto de Estado. Además, el Fiscal consideraba que el secreto de Estado se había opuesto de forma tardía y retroactiva, inmotivada y genérica violando las prerrogativas reconocidas al mismo por el artículo 112 de la Constitución italiana («Il pubblico ministero ha l'obbligo di esercitar el'azione penale»). El Fiscal pedía la anulación de una nota de 26 de julio de 2006 en la que el Primer Ministro señalaba que el secreto de Estado sobre los hechos vinculados con el secuestro había sido declarado ya por su predecesor en el cargo, por considerar que se trataba en realidad de una oposición retroactiva del secreto y también en la medida en que dicha nota se vinculaba a una nota de 30 de julio de 1985, del anterior Primer Ministro, en donde se establecía el secreto sobre la información y los documentos atinentes a las relaciones entre los servicios secretos italianos y extranjeros. Para el Fiscal, si se interpretase que esta nota impedía a la autoridad judicial (en este caso a la fiscalía) adquirir y utilizar cualquier información o documento que afectase a esas relaciones entre servicios de inteligencia, se le estaría imponiendo un deber de solicitar al Primer Ministro una derogación caso por caso de este secreto impuesto de manera tan genérica violando las prerrogativas del fiscal.

Los dos últimos conflictos de atribuciones se interponen en el año 2008 en relación con la fase del juicio oral donde se iba a juzgar a varios agentes de la CIA, del SISMI y a otros imputados por el secuestro y entrega (extraordinary rendition) de Abu Omar. El juez del Tribunal de Milán ( «Giudice monocratico della IV sezione penale del Tribunale Penale di Milano) revocó, por orden de marzo de 2008, su decisión de suspender el proceso y decidió proseguir con el mismo. Además, estableció, por orden de mayo de 2008, la sustitución del dossier D-19 completo por el que contenía tachaduras como material probatorio en la fase oral y admitió la petición de la acusación de interrogar a dos testigos sobre los hechos objeto del caso. 
El Primer Ministro alegó que la decisión de levantar la suspensión del procedimiento atentaba contra el principio de leal colaboración, según el cual el juez debería haber esperado a la decisión de la Corte sobre los demás conflictos de atribuciones para proseguir con el proceso. En relación a la prueba de testigos admitida por el juez, el Primer Ministro entendía que dicha prueba violaba el secreto de Estado. El Primer Ministro pidió la anulación de ambas órdenes y requirió a la Corte Costituzionale para que manifestara que no procedía la interpretación del juez del Tribunal de Milán según la cual el secreto de Estado que cubre las relaciones entre la CIA y el SISMI tendría como objeto la red de vastas relaciones entre la CIA y el SISMI pero no cubriría relaciones específicas en las que se hubiera incurrido en responsabilidad personal. Para el Primer Ministro esta concepción supondría invertir la regla de las relaciones existentes entre secreto de Estado y función jurisdiccional y afirmar la prevalencia de la competencia judicial para la averiguación de los delitos sobre la competencia del Primer Ministro para declarar secretas las fuentes de prueba.

En fin, en el juicio oral, los testigos propuestos por la acusación manifestaron que no podían dar testimonio porque su testimonio versaba sobre información cubierta por el secreto de Estado. Se basaban en una carta de 6 de octubre de 2008 del Primer Ministro en el que éste recordaba a todos los agentes o ex-agentes del SISMI llamados a dar testimonio que el secreto de Estado cubría cualquier relación entre el servicio de inteligencia italiano y los servicios de inteligencia extranjeros en el contexto de la tutela de las relaciones internacionales y que tenían la obligación de oponer el secreto de Estado en lo que tuviera que ver con dichas relaciones, aunque estuviera vinculado al secuestro de persona que venía siendo objeto del litigio. El testigo Scandone iba a ser interrogado sobre las eventuales órdenes dadas por el General Pollari, imputado en la causa, dirigidas a prohibir a sus inferiores el uso de medios ilícitos en la lucha contra el terrorismo y en particular de las extraordinary renditions. Al segundo testigo, Murgolo, el juez le pedía que repitiese lo ya dicho en la fase de instrucción sobre sus conversaciones con el imputado del SISMI Mancini, relativas a la involucración de este último en el secuestro y a su participación — la de Mancini- en una reunión con los americanos en Bolonia.

El Juez de Milán preguntó al Primer Ministro si confirmaba el secreto de Estado (siguiendo lo dispuesto en el artículo 202 C.p.p.) y éste así lo hizo mediante nota de 15 de noviembre de 2008, fundamentando la confirmación del secreto en la necesidad de preservar el crédito del servicio de inteligencia italiano en sus relaciones internacionales con otros organismos con los que éstos trabajan. Si no se preservara el secreto en este caso, señalaba el Primer Ministro, el servicio de inteligencia italiano podría quedar condenado al ostracismo por los servicios de inteligencia extranjeros con consecuencias graves para las posibilidades de desarrollar su actividad presente y futura. Además, también alegó que el secreto era necesario para protegerlas estructuras, organización y métodos del servicio de inteligencia. Según el Primer Ministro, el juez podría utilizar otras pruebas para alcanzar la verdad en el caso ya que el delito mismo no estaría cubierto por el secreto de Estado.

El juez del Tribunal de Milán ante esta respuesta interpuso, a su vez, un nuevo conflicto de atribuciones pidiendo que se anulara la nota de 15 de noviembre de 2008 y, en su caso, la carta de 6 de octubre de 2008, al considerar que esta confirmación 
del secreto le impedía desarrollar el pleno ejercicio de sus funciones. Para el juez, si el delito no estaba cubierto por el secreto tampoco debería estarlo las conductas de los imputados, pues constituirían elementos constitutivos de dicho delito. El juez entendía además que los dos actos de confirmación del secreto violaban el principio de proporcionalidad, puesto que ambos intereses (la credibilidad del servicio en el ámbito de sus relaciones internacionales con otros organismos homólogos y la protección de la estructura, organización y métodos del servicio de inteligencia) podían haberse garantizado haciendo una distinción entre la información inherente a las formas de organización y actuación del servicio o relaciones de carácter general e institucional con los servicios extranjeros, incluyendo eventuales acuerdos definitorios de líneas de actuación compartidas, y que permanecerían secretas, de las conductas concretas desarrolladas por particulares agentes o imputados y que tenían incidencia causal sobre el hecho delictivo.

La Corte Costituzionale estimó parcialmente los dos conflictos de atribuciones planteados por el Primer Ministro y desestimó los demás conflictos. Veamos la argumentación de la Corte.

\subsection{La doctrina derivada de la resolución de los conflictos de atribuciones por la Corte Costituzionale}

La Corte Costituzionale, en el fundamento jurídico tercero de la Sentencia 106/2009, recuerda su jurisprudencia previa sobre el control por los jueces ordinarios de los secretos de Estado. Esta jurisprudencia proviene de dos sentencias de los años setenta en las que la Corte hubo de resolver dos cuestiones de inconstitucionalidad planteadas por los jueces sobre los artículos 342 y 352 del Código procesal penal italiano de 1930, vigente entonces: la sentencia número 82 de 1976, de 14 de abril y la sentencia número 86 de 1977, de 24 de mayo (en esta última el juez consideraba que dichos artículos eran contrarios a los artículos 101, 102 y 112 de la Constitución Italiana en cuanto que obstaculizaban el recto ejercicio de la función judicial).

El artículo 342.3 C.p.p. admitía respecto del secreto administrativo o profesional que el juez controlase si la negativa a aportar determinados documentos por funcionarios públicos, empleados públicos o encargados de servicios públicos estaba justificada y si consideraba que no lo estaba podía ordenar el secuestro de dicha documentación, mientras que el número segundo de dicho artículo 342 C.p.p., en relación con el artículo 352.2 C.p.p., impedía al juez indagar sobre la justificación de la negativa a aportar documentos en el caso de los secretos de Estado. El artículo 352 C.p.p. regulaba la prueba de testigos en el proceso penal, y establecía que los funcionarios públicos, empleados públicos y encargados de un servicio público no podían ser interrogados sobre secretos políticos o militares relacionados con la seguridad del Estado o sobre cualquier otra información que claramente pudiera dañar la seguridad del Estado o el interés político, interno o internacional, del Estado ${ }^{6}$. La Corte rechazó ambas cuestiones de inconstitucionalidad.

6 Pueden encontrarse diversos comentarios a esta sentencia de 1977 de prestigiosos autores italianos en el propio volumen en el que se publica la sentencia de la Corte. Así, PISA, Paolo: «Ilsegreto di Stato di fronte 
Para la Corte Costituzionale la disciplina del secreto de Estado atañe al interés supremo de la seguridad del Estado desde el punto de vista de su personalidad internacional, esto es, al interés del Estado-comunidad (frente al Estado-aparato) a su integridad territorial, a su independencia y, ya en el límite, a su propia supervivencia. Intereses estos que están presentes y son prevalentes en todos los ordenamientos estatales — según la Corte Costituzionale-, cualquiera que sea su régimen político, y que se plasman en el ordenamiento jurídico italiano en la fórmula solemne del artículo 52 CI, que declara que la defensa de la patria es un deber sagrado del ciudadano ${ }^{7}$. La Corte reconoce que el secreto de Estado puede interferir con otros principios constitucionales, incluso aquellos que regulan la función jurisdiccional, pero la seguridad del Estado constituye un interés esencial de la comunidad que tiene carácter prevalente sobre cualquier otro, pues afecta a la existencia del Estado mismo, una de cuyas facetas es la jurisdiccional. Por ello la Corte Costituzionale estima que el Primer Ministro tiene un amplio poder en este campo, limitado únicamente por la necesidad de explicar al Parlamento las razones esenciales de la declaración u oposición del secreto y por la prohibición de oponer el secreto sobre hechos subversivos (destructivos del ordenamiento).

La Corte afirma que la individualización de los hechos, actos o informaciones que pueden comprometer la seguridad del Estado y que deben por ello permanecer secretos es producto de una valoración ampliamente discrecional que va más allá de la discrecionalidad puramente administrativa, puesto que afecta a la salus rei pubblicae y que por ello los jueces ordinarios — pues la Corte deja a salvo su competencia en materia de conflicto de atribuciones, y ya veremos qué papel asume en dichos conflictos, que es a lo dan respuesta las sentencias 106/2009 y 40/2012 - no pueden ejercer ningún control sobre la existencia o inexistencia del secreto de Estado ni sobre la forma en que se ha ejercido la competencia en materia de secreto de Estado. El juicio, dice la Corte, sobre los medios idóneos y necesarios para garantizar la seguridad del Estado es de naturaleza política, juicio que es connatural a los órganos y autoridades políticas pero no a los jueces. El poder judicial no puede sustituir al poder ejecutivo. El secreto de Estado queda pues sujeto a un control de naturaleza parlamentaria, pues es esta sede la que normalmente ejerce el control de fondo sobre las decisiones más graves e importantes del Ejecutivo, es donde está representado el pueblo, cuya soberanía es la que se puede ver atacada, y es el lugar donde se pueden adoptar las medidas más idóneas para garantizar la seguridad del Estado.

En fin, la Corte, haciendo referencia a una sentencia de 1998 (la sentencia 110/1998), aclara que la oposición del secreto de Estado por el Primer Ministro no impide al juez indagar sobre el delito en el ejercicio de la acción penal sino únicamente

alla Corte costituzionale: luci ed ombre in attesad ella "riforma" , Giurisprudenza costituzionale I, 1977, pp. 1206 y ss; ANZON, Adele: «Interrogati sui riflessi sostanziali della nozione di segreto di Stato individuata dalla Corte Costituzionale», Giurisprudenza costituzionale, I, 1977, pp. 866 y ss y SANDULLI, Aldo M.: «Note minime in tema di segreto di Stato», Giurisprudenza costituzionale, I, 1977, pp. 1200 y ss.

$7 \mathrm{La}$ Corte hace referencia a la necesidad de que el concepto de defensa de la Patria y de la seguridad del Estado se delimite teniendo en cuenta otros principios indispensables del ordenamiento jurídico italiano, como la forma de Estado que establece el artículo 1 de la Constitución, esto es, que Italia es una República democrática, o la norma que recogen la unidad e indivisibilidad del Estado (art. 5 CI). 
adquirir o utilizar (directa o indirectamente) los elementos de prueba cubiertos por el secreto de Estado.

En el fundamento jurídico cuarto de la sentencia 106/2009, la Corte defiende la continuidad de esta jurisprudencia por la que se excluye el control jurisdiccional de los secretos de Estado, quedando a salvo el papel que pueda desempeñar ella misma.

Entrando a resolver el caso concreto planteado, la Corte afirma que si bien el secuestro de la documentación del SISMI por la fiscalía de Milán fue un acto legítimo, puesto que nadie en la sede del SISMI opuso el secreto de Estado al requerimiento, en el momento en el que el SISMI envió el dossier con diversas partes tachadas la fiscalía debería entonces, bien haber devuelto el dossier completo y haber incorporado el dossier con las tachaduras al proceso, bien haber pedido la confirmación del secreto de Estado al Primer Ministro. La Corte equipara el envío del dossier con frases enteras eliminadas al actado de oposición del sectreto de Estado. Opuesto el secreto de Estado, la fiscalía no debería haber utilizado la documentación completa ni directa ni indirectamente pues se trataba de proteger intereses primarios, que afectaban a la salus rei pubblicae y que justificaban la oposición erga omnes del secreto. La Corte considera que al no haber pedido la fiscalía la confirmación y haber basado los siguientes actos de investigación y la petición de que se iniciara la instrucción en el dossier completo, la fiscalía habría vulnerado las prerrogativas del Primer Ministro. Por otro lado, la Corte no considera que el secuestro de Abu Omar pudiera ser incluido en el tipo de actos subversivos del orden constitucional, por mucho que dicho acto sea contrario a los principios del Estado de Derecho. Además, para la Corte, el secreto de Estado no protegería el acto delictivo sino que impediría la utilización de determinados medios de prueba en el proceso (fundamento jurídico octavo).

En cuanto a la alegación de que el secreto de Estado opuesto vendría a proteger únicamente las líneas generales y estratégicas de colaboración entre los servicios implicados, la Corte declara en el fundamento jurídico noveno de la sentencia que habría que entender que el secreto también cubría los intercambios de información y los actos de recíproca asistencia que se produjeran en operaciones concretas de los servicios de inteligencia. El secreto de Estado cubriría tanto una como otra información dado que el Primer Ministro había declarado secreto cualquier aspecto referido a las relaciones entre el servicio secreto italiano y los servicios secretos extranjeros. La Corte se hace eco de la declaración del Primer Ministro según la cual las relaciones entre los servicios de inteligencia constituyen uno de los puntos de mayor sensibilidad y requieren de la máxima reserva. En razón de todo ello, la Corte declara que no debería haber tenido lugar la prueba de testigos que la fiscalía dispuso y que se había vulnerado con ello las prerrogativas del Primer Ministro.

En el mismo sentido, el juez del Tribunal de Milán alegaba que su interrogatorio no versaba sobre las relaciones entre servicios de inteligencia sino sobre lo que el testigo conocía de la participación del imputado Mancini en el secuestro. Sin embargo, la Corte entiende que la petición del juez era que el testigo reprodujese lo que Mancini le había contado sobre una reunión habida en Bolonia con los servicios de inteligencia estadounidenses y que sobre ello recaía el secreto de Estado que el Primer Ministro había establecido en relación con las relaciones internacionales del SISMI con otros servicios de inteligencia, incluso si esas relaciones en algún aspecto tenían conexión con el 
presunto secuestro de persona. En definitiva, los testigos Scandone y Murgolo habrían opuesto el secreto para preservar esas relaciones internacionales con otros servicios de inteligencia extranjeros y para tutelar la estructura y la forma de operar del SISMI a decir del Primer Ministro, a lo que la Corte da su visto bueno, señalando que el secreto no tenía como objeto el delito de secuestro.

Por último, la Corte se pronuncia sobre la alegación del juez del Tribunal de Milán que consideraba que se había vulnerado el principio de legalidad y el de proporcionalidad en la oposición y confirmación del secreto en la prueba de testigos. Recordemos que el órgano judicial entendía que la credibilidad del servicio de inteligencia en el ámbito de sus relaciones internacionales con otros organismos homólogos y la protección de las formas de organización y actuación del mismo podían haberse garantizado haciendo una distinción entre la información inherente a tales formas de organización y actuación del servicio y a sus relaciones de carácter general e institucional con los servicios extranjeros, incluyendo eventuales acuerdos definitorios de líneas de actuación compartidas, y que permanecerían secretas, de las conductas concretas desarrolladas por particulares agentes o imputados y que tenían incidencia causal sobre el hecho delictivo. Para la Corte en realidad esta alegación encierra la petición de que la Corte realice un control sobre las razones de la declaración/confirmación del secreto y la Corte no se va a considerar legitimada para ello (esta es la parte a nuestro juicio más interesante de la sentencia).

La Corte (fundamento jurídico duodécimo) vuelve a repetir, pero esta vez en relación con un posible control del secreto no por los tribunales ordinarios, sino por ella misma, que la determinación de los actos, informaciones o actuaciones que deben permanecer en secreto por razones de seguridad del Estado es el producto de un juicio ampliamente discrecional que va más allá de la discrecionalidad puramente administrativa puesto que toca la salus rei pubblicae y que el juicio sobre los medios necesarios para garantizar la seguridad del Estado pertenece al Primer Ministro bajo el control del Parlamento. Debe ser la Comisión parlamentaria competente (el COPASIR actualmente) la que lleve a cabo el control de la motivación del acto de confirmación del secreto, incluido el control de la proporcionalidad de los medios utilizados con respecto al fin perseguido, señala la Corte, pues el Parlamento es la sede normal de control sobre el fondo de las decisiones más sensibles y graves tomadas por el Ejecutivo. La Corte manifiesta que su papel en el conflicto de atribuciones, de conformidad con lo dispuesto en el artículo 202.7 C.p.p. ${ }^{8}$, sería valorar la subsistencia o insubsistencia de los requisitos del secreto de Estado formalmente opuesto y confirmado, no hacer una valoración sobre el fondo y sobre cómo se ha desarrollado concretamente el proceso de declaración, oposición y confirmación del secreto de Estado, puesto que este juicio estaría reservado al Parlamento. Si el secreto subsiste y la información cubierta por el secreto era esencial para la continuidad del proceso y no existieran fuentes de prueba independientes sobre

8 El artículo 202.7 C.p.p. de acuerdo con la redacción dada por la Ley núm. 124/2007 simplemente señala que cuando se platea el conflicto de atribuciones contra el Primer Ministro en esta materia, si en el conflicto se resuelve la insubsistencia del secreto de Estado, el Primer Ministro no podrá volver a oponerlo con respecto al mismo objeto, y si se resuelve que el secreto subsiste la autoridad judicial no podrá ni adquirir ni utilizar, directa o indirectamente los actos o documentos sobre los que se haya opuesto el secreto. 
las que basarse, el juez debe declarar que no se puede proceder por la existencia del secreto de Estado.

Tras la resolución del conflicto de atribuciones por la Corte Costituzionale el juicio en Milán se reabrió. El juez no pudo utilizar la información que el Ejecutivo consideró secreta. El juicio acabó con la condena de 26 agentes de la CIA por el delito de secuestro y detención ilegal, pero debido al secreto de Estado, los agentes del servicio secreto italiano fueron absueltos en primera instancia ${ }^{9}$. Finalmente en apelación el Tribunal de Apelaciones de Milán condenó al ex director del SISMI, Pollari, y a su número dos, Mancini, a diez y nueve años de cárcel, respectivamente.

\section{LA SENTENCIA DE LA CORTE COSTITUZIONALE NÚMERO 40/2012, DE 29 DE FEBRERO}

Esta sentencia viene a resolver un nuevo conflicto de atribuciones, esta vez entre el juez de instrucción de Peruggia y el Primer Ministro italiano. En el secuestro de la documentación del SISMI al que ya hicimos referencia en el caso anterior, se descubre un archivo que contenía numerosos dossiers que recogían datos sobre la vida, la actividad y la orientación de magistrados, funcionarios estatales, periodistas y parlamentarios y sobre la actividad de sindicatos y asociaciones de magistrados, incluida una asociación de magistrados europeos, por considerarlos de la oposición. Se abre un procedimiento penal y en él se procesa a Pollari, ex director del SISMI (el antiguo servicio de inteligencia italiano) y a Pompa, primero colaborador y luego trabajador del SISMI, como responsables de haber recabado tal información. A los procesados, se les acusa de un delito de malversación de fondos públicos por utilizar medios materiales y humanos del SISMI y ponerlos al servicio de actividades claramente extrañas a las finalidades institucionales del servicio; además se les acusa de un delito de violación de correspondencia [por haberse hecho con las comunicaciones informáticas de la asociación de magistrados europeos (la MEDEL)].

Los dos sujetos procesados fueron interrogados y alegaron que no podían desvelar datos esenciales para demostrar su inocencia por estar esta información cubierta por el secreto de Estado ya que afectaba a la estructura, métodos operativos y organización del servicio (a directrices y órdenes impartidas por las autoridades gubernativas y por el director a los empleados del organismo, a la posición de Pompa en el servicio, a los recursos utilizados para su actividad, a su relación con otros agentes, o a la relación de la documentación reclamada con la seguridad del Estado y su relevancia para las actividades del SISMI). Por ello los procesados opusieron el secreto de Estado. El fiscal pidió entonces la confirmación, conforme a la nueva ley de 2007, del secreto de Estado sobre cuatro circunstancias que consideraba esenciales para la continuidad del proceso: a) si el Gobierno había financiado y, en qué forma o modo, la presunta sede del SISMI en via Nazionale, dirigida por Pompa, donde se habían encontrado los archivos en cuestión; b) si se había retribuido económicamente de cualquier forma a Pompa y a otro colaborador

9 TOMMASO F. GIUPPONI \& Federico FABBRINI: Intelligence agencies and the State secret privilege: the Italian experience, icl-journal, vol. 4, 2010, pp. 443-466, p. 464. 
del SISMI, Tontodimamma; c) si se habían impartido órdenes o directrices a ambos y d) si se habían impartido órdenes o directrices a los dos para que recogieran información sobre magistrados italianos y extranjeros.

El Primer Ministro confirmó el secreto de Estado, no sobre la existencia de financiación pero sí sobre la forma y el modo de financiación de la presunta sede del SISMI; también sobre el modo y forma de retribución de Pompa y Tontodimamma (que no sobre la existencia de retribución) y, finalmente, sobre las directrices y órdenes impartidas en el Servicio a Pompa y Tontodimamma. La confirmación del secreto se basó en la exigencia de la tutela de las estructuras, organización y métodos operativos del SISMI. Este interés estaría entre los cubiertos por el secreto de Estado según el Decreto del Primer Ministro de 8 de abril de 2008, que concreta los intereses que de acuerdo al artículo 39 de la Ley 124/2007 pueden ser protegidos por el secreto.

El juez de instrucción entendió que esa confirmación del secreto vulneraba el ejercicio de las funciones jurisdiccionales. Veremos sus alegaciones conforme desgranamos la argumentación de la Corte Costituzionale. La Corte falla a favor del Primer Ministro y rechaza el conflicto planteado por el juez.

La Corte reitera su jurisprudencia de la sentencia 106/2009 en el sentido de que el secreto protege intereses supremos del Estado comunidad y es instrumento necesario para conseguir la seguridad del Estado, interés esencial que tiene absoluta prevalencia sobre cualquier otro (y hace referencia de nuevo a los artículos 1,5 y 52 de la Constitución italiana).

La Corte aborda el tema del derecho de defensa y el derecho a la prueba cuando ésta versa sobre información secreta. Según la sentencia 40/2012, tras la introducción de la nueva ley de 2007 sobre el servicio de inteligencia y el secreto de Estado, los sujetos imputados o procesados están obligados a no declarar sobre hechos cubiertos por el secreto de Estado. El artículo 41 de la Ley 124/2007 dispone que los funcionarios públicos, los empleados públicos y los encargados de un servicio público no pueden hacer referencia a hechos cubiertos por el Secreto de Estado. En la regulación anterior sólo los testigos estaban sometidos a esa obligación de no declarar y se entendía que los procesados y los imputados podían elegir entre no declarar o hacerlo sobre hechos cubiertos por el secreto de Estado para probar su inocencia. El juez de Peruggia que planteó el conflicto de atribuciones defendía que este régimen seguiría siendo aplicable aún con la entrada en vigor del artículo 41 de la Ley de 2007 porque éste no habría afectado a los principios en juego. Según la jurisprudencia anterior, en el caso de que el procesado o imputado declarase sobre hechos o informaciones cubiertas por el secreto de Estado no se le hacía responsable del delito de revelación de secretos, entendiendo que concurría la eximente de ejercicio de un derecho de rango primario, el derecho de defensa. Para la Corte Costituzionale, esto obligaría al imputado o procesado a realizar una ponderación entre su derecho a la defensa y el supremo interés de la seguridad del Estado y a correr con los costes de su decisión. Revelando el secreto el imputado o procesado podría obtener la absolución en detrimento de la seguridad nacional, mientras que si callaba preservaba esta última, exponiéndose al riesgo de una condena injusta (fundamento jurídico $6^{\circ}{ }^{\circ}$. Con el nuevo régimen jurídico, dice la Corte, el Estado, velando por su conservación, requiere a la persona procesada el silencio sobre la información secreta (artículo 41 Ley núm. 124/2007), pero le protege también del riesgo de una indebida 
inculpación, pues si las pruebas son esenciales para el proceso, el juez debe declarar que no se puede proceder con la causa.

Para el juez de Peruggia, lo dispuesto en el artículo 41 de la Ley 124/2007 no puede servir como una eximente en blanco. La Ley en otros artículos prevé eximentes para determinadas conductas de los agentes de los servicios secretos pero siempre bajo la condición de que las conductas sean realizadas para cumplir con los fines del servicio y previa autorización escrita del Primer Ministro (artículos 17, 18, 19 y 39 de la ley). Los agentes del servicio imputados o procesados por la comisión de un delito no pueden sustraerse al juicio penal simplemente alegando que existen pruebas de su inocencia que no se pueden aportar debido a que están cubiertas por el secreto de Estado (antecedentes de hecho $4^{\circ}$ ). Para evitar esto, defiende el juez de Peruggia, la Corte Costitucionale debería verificar que realmente existen las pruebas alegadas y la legitimidad de que sean declaradas secretas. Ello no implicaría un control sobre el fondo del ejercicio de la competencia de declarar secreta cierta información (pues la Corte excluye ese control en su sentencia 106/2009) sino que se trataría de contralar que no hay un abuso del secreto de Estado. La Corte — defiende el juez de Peruggia — podría llevar a cabo este control puesto que está legitimada para pedir al Primer Ministro que le muestre la información secreta, ya que el secreto de Estado no le es oponible (artículo 41.8 de la Ley 124/2007).

Frente a esta argumentación, la Corte contesta que no le corresponde determinar si el secreto se opuso por los imputados o procesados de forma apropiada y útil al fin perseguido, ni determinar de qué forma influye en el proceso penal en curso la confirmación del secreto de Estado, debiendo realizar el juez dicha valoración. En realidad, señala la Corte, el juez deberá determinar la coherencia y la plausibilidad de los planteamientos del imputado o procesado, aplicando las normas procesales pertinentes ya que el hecho de que alegue que existen pruebas que determinan su inocencia puede no ser fundamental para la continuidad del proceso. Deberá ser el juez el que valore estos aspectos. El Primer Ministro, al confirmar el secreto de Estado no se pronuncia — dice la Corte- sobre la relevancia de la prueba para el proceso, sino sólo sobre la posibilidad de que dicha información pudiera dañar la seguridad nacional. La valoración de la esencialidad de la prueba para el proceso corresponde al juez. La Corte no entra a determinar, como le pedía el juez de Peruggia, (antecedentes de hecho 4), si las pruebas realmente existían y si era legítima la declaración del secreto sobre las mismas ${ }^{10}$.

El juez de Peruggia entendía que la información declarada secreta no podían ser cubierta por el secreto de Estado porque se trataba de información sobre financiación,

10 Givanni Salvi, en un comentario a la Sentencia 106/2009, que por primera vez trató este tema, pero sólo como obiter dicta y sin entrar en el detalle en el que entra la Sentencia 40/2012, se muestra crítico con esta nueva doctrina. Cuando el imputado alega que no puede declarar por existir un secreto de Estado y que la información secreta es esencial para eximirle de responsabilidad y el secreto de Estado es confirmado, ¿quién controlará que ello es verdad? No lo hará el juez penal porque le está vedado conocer del secreto de Estado, tampoco el Ejecutivo, pues no tiene competencia para decidir sobre la relevancia de la prueba en el proceso, la Corte, dice Salvi, sin conocer todavía lo que mantuvo en la Sentencia 40/2012, no parece que vaya a hacerlo dado el papel que ha asumido en el control del secreto de Estado, y parece difícil que el Parlamento vaya a ser el que decida esta cuestión.

SALVI, Giovanni: «La Corte e il Segreto de Stato», en http://www.astrid-online.it/giustizia-/studi--ric/

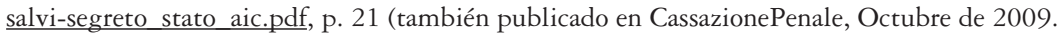


órdenes y directrices del servicio de inteligencia relativas a actividades ajenas a la función institucional del Servicio. La Corte contesta que en realidad el Primer Ministro no confirma el secreto sobre las actividades ilegales de los imputados sino sobre las informaciones cuya difusión podría exponer a una indebida publicidad los métodos y modalidades de organización del servicio de inteligencia, declarados secretos por el Decreto del Primer Ministro de 8 de abril de 2008. Además, la Corte mantiene que la petición de confirmación del secreto, incluida la petición relativa a las órdenes y directrices de recopilar información sobre magistrados italianos y extranjeros, se hizo en términos muy genéricos, sin hacer referencia a nombres de los magistrados o a criterios de selección de los sujetos espiados, ni a la finalidad por la que se habría recopilado dicha información, por lo que no cabe interpretar que el Primer Ministro intentó confirmar el secreto sobre los hechos subyacentes al proceso sino que entiende la Corte que el Primer Ministro contestó en los mismos términos genéricos y con la misma indefinición con la que se había planteado la consulta por el juez de Peruggia (según el Primer Ministro la revelación de las órdenes y directrices sobre el asunto en cuestión pondrían de manifiesto indirectamente los medios y las técnicas operativas del servicio de inteligencia italiano).

En relación con los fondos reservados, la Corte declara que el principio de prevalencia de la seguridad del Estado tiene vigencia también respecto del uso que se haga de los fondos reservados (fundamento jurídico 13).

El juez de Peruggia alegaba que el hecho de que el acto de confirmación del secreto fuera expresión de discrecionalidad política justificaría que el juez ordinario no pudiese conocer de los mismos, como mantuvo la sentencia 86/1977 pero no impediría el control de la Corte Costituzionale. De conformidad con la normativa sobre el secreto de Estado aprobada por la Ley 124/2007, que establece algunas causas de justificación para actos que de otra forma se considerarían ilegales, pero no para todo tipo de actos realizados por los servicios de inteligencia, y con el principio de proporcionalidad, los métodos y la organización del servicio de inteligencia no pueden ser objeto de tutela indiscriminada, mantenía el juez, sobre todo cuando detrás hay conductas de los agentes de inteligencia que tienen naturaleza delictiva. El secreto de Estado debe ser instrumental respecto a los intereses prevalentes que se quiere salvaguardar. El acto de confirmación del secreto de Estado por el Primer Ministro debería estar motivado (art. 41.5 Ley 124/2007) de forma congruente, debiendo explicar el Primer Ministro las razones por las que debe prevalecer la tutela de la estructura, organización y métodos del servicio de inteligencia sobre otros intereses salvaguardados por la norma constitucional. La Corte Costituzionale debería controlar el correcto ejercicio de la discrecionalidad por el Primer Ministro a la luz de los principios constitucionales y de su correcta ponderación.

La Corte Costituzionale rechaza llevar a cabo tal control. La Corte repite su argumentación de la Sentencia 106/2009, y establece que el juicio del Primer Ministro sobre los medios necesarios o útiles para garantizar la seguridad del Estado, por su carácter político y ampliamente discrecional, debe ser controlado únicamente por el Parlamento. La Corte se pronunciará únicamente sobre la existencia o inexistencia de los presupuestos necesarios para la subsistencia o insubsistencia del secreto de Estado formalmente opuesto o confirmado y no realizará consideraciones de fondo sobre los motivos de la interposición del secreto (fundamento jurídico 14). La obligación 
de motivación del acto de confirmación del secreto existe, ciertamente, pero según la Corte la motivación es diferente frente al Parlamento y frente a la autoridad judicial. La motivación frente al juez no persigue permitir un control sobre la forma en que se ha ejercido la competencia de declaración o confirmación del secreto de Estado. Se trata simplemente de justificar en términos coherentes y plausibles que la información puede reconducirse a los intereses tutelados por el secreto de Estado ya que se obstaculiza con ello el ejercicio de la función jurisdiccional. Sólo cuando la motivación, defiende la Corte, no se dirija a justificar esa protección de la seguridad del Estado, cabrá recurrir a la Corte a través del conflicto de atribuciones.

Por todo ello la Corte desestima el conflicto de atribuciones planteado por el Juez de Peruggia.

\section{ANÁLISIS FINAL}

Por primera vez la Corte Costituzionale debe enfrentarse a la petición de que entre a conocer de la legitimidad del secreto de Estado. Anteriormente la Corte había declarado que el poder judicial no podía ejercer ningún control sobre el secreto de Estado pero nunca se había tenido que enfrentar a su propio papel en el control jurisdiccional del mismo. El hecho de que la Corte lleve a cabo por primera vez este control sobre el secreto de Estado es, sin duda, positivo. Sin embargo, la Corte se muestra, en nuestra modesta opinión, demasiado deferente hacia el Ejecutivo.

En las sentencias descritas, la Corte Costituzionale reconoce que el secreto de Estado puede interferir con otros principios constitucionales, incluso aquellos que afectan a la función jurisdiccional, pero estima que la seguridad del Estado constituye un interés esencial de la comunidad, que tiene carácter prevalente sobre cualquier otro interés (bien o derecho) pues afecta a la existencia del Estado mismo, una de cuyas facetas es, precisamente, la jurisdiccional. Sin embargo, el argumento según el cual cuando el Ejecutivo apela al secreto de Estado siempre está en juego la existencia del Estado es peligroso y puede hacernos infravalorar nuestros derechos y libertades sobreestimando la seguridad del Estado. Muchas veces esto no es necesariamente así, como demostró el caso de «los papeles del CESID» en España y como demuestra la clasificación excesiva de información que existe, al menos en España, si no en todos los países (en España, desde luego, pues en nuestro país no existe un mecanismo de desclasificación automática de la información clasificada debiendo ser el Gobierno el que desclasifique individualmente cada documento o información secreta —arts. 4 y 7 de la Ley de Secretos Oficiales—) ${ }^{11}$.

11 Ley 9/1968, de 5 de abril modificada por Ley 48/1978. De hecho, durante el Gobierno Socialista Carme Chacón como Ministra de Defensa dirigió un proyecto para desclasificar documentos de los archivos militares. Miles de documentos siguen siendo secretos, documentos que datan de la Guerra Civil e incluso de épocas precedentes. La Ministra Chacón quiso desclasificar nada menos que 10000 documentos pero finalmente estos documentos no se desclasificaron. El nuevo Ministro de Defensa, Pedro Morenés, ha aparcado la desclasificación por entender que la difusión de algunos de estos documentos podría perjudicar las relaciones diplomáticas o dañar a terceros (es interesante leer las noticias de los periódicos para conocer la naturaleza de los documentos que se iban a desclasificar y entender la excesiva clasificación de documentos que existe en nuestro país). http://elpais.com/diario/2008/08/10/espana/1218319205 850215.htmlhttp://politica.elpais. 
Además, no se puede concebir la necesidad de seguridad como necesidad de preservación del Estado sin ligarlo a los valores esenciales del mismo. La invocación de la supervivencia del Estado podría convertirse en un dogma de fe que evitase el debate en la sociedad sobre las formas en las que se quiere preservar la supervivencia de la comunidad y sobre los problemas morales relacionados con esta cuestión. En nombre de la seguridad del Estado podría llegarse a propugnar el sacrificio de bienes y derechos fundamentales protegidos por el ordenamiento jurídico que forman parte de su esencia y, por esa vía, conducir a la desaparición del Estado, no en sentido físico, pero si como espacio de convivencia articulado sobre derechos y libertades que por sí mismos deben constituirse también en objeto directo de protección y para cuyo fin el propio Estado parece instituido ${ }^{12}$.

En nuestra opinión, el punto de partida correcto para una evaluación de la legitimidad del secreto de Estado pasa por entender que los derechos fundamentales de los ciudadanos son un componente esencial de la propia seguridad que se pretende ${ }^{13}$. Como decía Carl Friedrich, la historia del constitucionalismo es, desde sus comienzos, la historia de la lucha por someter el poder político a reglas que conduzcan al imperio de la razón (bajo la Ilustración encarnada por la Ley), y no al simple imperium de los gobernantes o «razón de Estado», que (frente a lo que sugiere su nombre) es únicamente la que encarnan quienes se encuentran a la cabeza de la comunidad política. «La razón de estado constitucional es en último análisis cosa de ordenación cada vez más eficaz de un gobierno con arreglo a Derecho» ${ }^{14}$. Pero el constitucionalismo no implica sólo una lucha contra la arbitrariedad del poder político, sino que ha ido librando también una batalla sin cuartel en favor del reconocimiento (primero) y la potenciación (después) de los derechos de los ciudadanos, transformados poco a poco en derechos dentro del Estado y no frente al Estado. Por eso, la seguridad del más íntimo yo — continua diciendo el mismo autor- «es más vital para la seguridad y supervivencia de un orden constitucional que cualquier frontera o cualquier secreto. Para cualquier comunidad edificada sobre la fe en los derechos humanos, la tarea de supervivencia y seguridad se convierte en la defensa del más recóndito "yo" tanto o más que en la de las fronteras exteriores" ${ }^{15}$. En este sentido, creemos que la Corte Costituzionale italiana debería haber ido más allá en su control de los secretos de Estado.

La Corte Costituzionale estima que el Primer Ministro tiene un amplio poder en este campo de los secretos de Estado, limitado únicamente por la necesidad de explicar al Parlamento las razones esenciales de la declaración u oposición del secreto

com/politica/2011/12/05/actualidad/1323119437_235554.htmlhttp://www.cadenaser.com/espana/articulo/ defensa-aparca-desclasificacion-10000-documentos-secretos/csrcsrpor/20120529csrcsrnac 1/Tes

12 OTERO GONZÁLEZ, M. ${ }^{a}$ del Pilar: La revelación del secreto de Estado en los procedimientos penales (violación de secretos por funcionario), Tirant lo blanch, Valencia, 2000, p. 48; LEIGH, Ian y LUSTAGARTEN, Laurence: In from the cold: national security and parliamentary democracy, ClarendonPress, Oxford, 1994, pp. 5 a 12.

13 LEIGH, Ian y LUSTGARTEN, Laurence: In from the cold..., p. 9. SALVI, Giovanni: «La Corte e ilSegreto de Stato», en http://www.astrid-online.it/giustizia-/studi--ric/salvi-segreto_stato_aic.pdf, p. 12 (también publicado en CassazionePenale, Octubre de 2009.

14 FRIEDRICH, Carl J.: La filosofía del Derecho, Fondo de Cultura Económica, México, Buenos Aires, 1964 , p. 412.

15 FRIEDRICH, Carl J.: Ibidem. 
y por la prohibición de oponer el secreto sobre hechos subversivos (destructivos del ordenamiento). Para la Corte, la individualización de los hechos, actos o informaciones que pueden comprometer la seguridad del Estado y que deben por ello permanecer secretos es producto de una valoración ampliamente discrecional que va más allá de la discrecionalidad puramente administrativa, puesto que afecta a la salus rei pubblicae. Por eso la Corte se declara competente únicamente para pronunciarse sobre la existencia o inexistencia de los presupuestos necesarios para la subsistencia o no del secreto de Estado formalmente opuesto o confirmado y no realiza consideraciones de fondo sobre los motivos de la interposición del secreto. En definitiva, la Corte se limita a analizar que se cumplen los elementos formales del acto de clasificación o confirmación del secreto de Estado (la competencia y el procedimiento) y que se alega la protección de un interés relacionado con la seguridad del Estado, pero nada más. Ejercita un control externo, formal, centrado en el cumplimiento de los requisitos legales para confirmar el secreto pero no en el fondo de la motivación de la declaración del secreto de Estado. En la doctrina italiana se ha llegado a decir que la Corte juega en este caso un papel meramente ornamental ${ }^{16}$ y que al no realizar un control de fondo sobre la motivación del acto de clasificación se arriesga a reducir el mecanismo del control del secreto de Estado a través del conflicto de atribuciones a un mecanismo inútil ${ }^{17}$.

El secreto de Estado es un instrumento de la política de seguridad y defensa del Estado, no una forma de hacer política, sino un mecanismo de protección de esos bienes jurídicos. Al margen de la capacidad orientadora y emprendedora que tiene el Gobierno a la hora de hacer política de seguridad y defensa, estos conceptos no significan cualquier cosa que el Gobierno quiera que signifiquen sino que el marco en el que se mueve esta rama de la política se va concretando a través de instrumentos normativos. Ciertamente estos instrumentos normativos no son muy densos en cuanto a su regulación, lo que implicará que el control no podrá ser exhaustivo; pero esa falta de densidad no significa nada más. El concepto de seguridad del Estado es un concepto jurídico indeterminado que limita sin duda la competencia del Primer Ministro en este campo y que puede ser objeto de control por la Corte Costituzionale. Es cierto que estamos ante un concepto que deja un amplio margen de apreciación al Ejecutivo pero el control de conceptos jurídicos indeterminados no es ajeno a la labor de los Tribunales Constitucionales (pensemos si no en la extraordinaria y urgente necesidad en el caso del DecretoLey $)^{18}$. La Corte debería haber analizado si la información que se ocultaba tras el secreto

16 FANCHIOTTI, Vittorio: «Il gusto (amaro) del segreto», Giurisprudenza Costituzionale, vol. 2, 2009, pp. 1033-1042, p. 1040.

17 GIUPPONI, Tommaso F. y FABBRINI, Federico: «Intelligence agencies and the State secret privilege: the Italian experience», icl-journal, vol 4, 2010, pp. 443-466, p. 465.

18 Adele Anzon defiende que la Corte es precisamente la más indicada para llevar a cabo este control, dado que no es una autoridad judicial cualquiera, y que tiene la competencia de controlar actos, dice, típicamente políticos, tales como las leyes. ANZON, Adele: «Il segreto di Stato ancora una volta tra Presidente del Consiglio, autorità giudiziaria e Corte Costituzionale» Giurisprudenza Costituzionale, vol. 2, 2009, pp. 1020-1033, p. 1031. Salvi por su parte defiende que la única interpretación posible de la nueva normativa de 2007, que expresamente menciona el conflicto de atribuciones y la no oposición del secreto de Estado frente a la Corte, es la de entender que la Corte debería haber entrado a analizar si se habían respetado los límites objetivos del Secreto de Estado y el juicio de proporcionalidad en la confirmación del Secreto en el caso concreto. SALVI, Giovanni: «La Corte...», p. 27. 
era merecedora de tal calificación o no lo era (recordemos que a la Corte no le es oponible el secreto de Estado, aunque en los casos plantados la Corte no hace uso de su competencia para acceder al secreto). Una vez establecido si la información secreta realmente afectaba a la seguridad y defensa del Estado (entrando sobre el fondo del asunto) la Corte debería haber determinado si la difusión de la misma podía realmente dañar la seguridad o defensa del Estado. Finalmente, se le reprocha a la Corte el no haber llevado a cabo una ponderación de los intereses en juego y haber mantenido una postura minimalista o demasiado deferente hacia el Ejecutivo ${ }^{19}$.

La Corte había declarado en su sentencia núm. 86/1977 que la potestad del Ejecutivo en este ámbito no era ilimitada y que el Ejecutivo debería justificar que el secreto se dirige a proteger los intereses supremos del Estado-comunidad y, en el caso concreto, explicar cómo esos intereses se verían afectados en un análisis de medio a fin (Salvi lo define como el principio de concreción del secreto sobre la base del principio de proporcionalidad). Pues bien, como señala Salvi, en el caso de la Sentencia 106/2009 se confirma el secreto con base en una declaración genérica hecha por el Primer Ministro en 1985 que declaraba secretas las relaciones entre el servicio de inteligencia italiano y otros servicios homólogos, pero no se concreta cómo podrían afectar los documentos y testimonios involucrados en el caso a dichas relaciones y, añado, tampoco se segrega aquella información sobre el secuestro y la detención ilegal que podría difundirse sin afectar a dichas relaciones ${ }^{20}$. Se cubre con el velo del secreto genéricamente toda la información sin justificar cómo peligraban los bienes que se pretendía proteger con el secreto en el caso concreto.

La declaración de que todo aquello que pueda afectar a las relaciones de los servicios de inteligencia italiano con los servicios de inteligencia extranjeros de manera genérica queda legítimamente amparado bajo el manto del secreto significa excluir casi cualquier información en manos de los servicios de inteligencia del conocimiento de los jueces puesto que hoy en día casi todos los servicios de inteligencia trabajan conectados con otros servicios de inteligencia extranjeros. Por otro lado, cuando esas relaciones cubren actos como el secuestro de persona para trasladarla a un país en el que pueda ser torturada, no es legítima la oposición del secreto. Como señalaba Dick Marty en su informe complementario a la propuesta de resolución de la Asamblea Parlamentaria del Consejo

19 GIUPPONI, Tommaso F. y FABBRINI, Federico: «Intelligence agencies...», p. 465. En este sentido, el Magistrado Xiol Rios en su voto particular a la Sentencia de 4 de abril de 1997 en el recurso 726/1996 señalaba que «la técnica de ponderación de derechos debe llevar al «sacrificio del valor» constitucional seguridad del Estado cuando el principio de proporcionalidad (pilar básico en la técnica de ponderación de derechos) así lo exija. Cerrar el paso a esta afirmación, recabando para el Gobierno una «exclusividad en la autoría de los actos políticos exenta por principio del control jurisdiccional encaminado a evitar el sacrificio de los derechos fundamentales», sería (...) grave, pues equivaldría a recluir el mundo de las decisiones políticas, en este caso el de las decisiones de gobierno sobre los secretos de Estado, en el mundo cerrado a su propia lógica política ajena a la lógica del Estado de derecho. Esto sería muy próximo a la recuperación del concepto de la «razón de Estado», que precisamente por constituir la reivindicación de un sistema informado por unos principios políticos autónomos respecto del sistema jurídico [...] se considera como la negación misma del Estado de derecho [...].

Sobre los «juicios de ponderación» vid., por todos, RODRÍGUEZ de SANTIAGO, La ponderación de bienes e intereses en el Derecho administrativo, Madrid 2000, p. 39 y ss.

20 SALVI, Giovanni: «La Corte...» pp. 14, 15, y 21. 
de Europa sobre «El abuso del secreto de Estado y de la seguridad nacional: obstáculos al examen parlamentario y jurisdiccional de las violaciones de los derechos humanos» ${ }^{21}$, un Estado democrático basado en el imperio de la ley debe contar con mecanismos para llegar hasta el fondo en el caso de violaciones graves de los derechos humanos (como era el caso Abu Omar, en el que se condenó a los agentes de la CIA pero no se pudo hacer lo mismo con los agentes del servicio de inteligencia italiano por la oposición del secreto de Estado). La Asamblea reconoce la necesidad de los Estados de proteger la seguridad nacional mediante el secreto pero considera que la información concerniente a la responsabilidad de agentes del Estado que han cometido serias violaciones de los derechos humanos (como asesinato, desaparición forzosa, tortura o secuestro), no debería estar cubierta por el secreto. Por otro lado, señala que no hay razón por la que se deba confiar menos en los órganos judiciales o el Parlamento que en el Ejecutivo cuando de proteger los secretos se trata. La Asamblea celebra la cooperación entre los servicios secretos de diferentes países, porque la considera indispensable hoy en día para luchar contra el crimen organizado y el terrorismo pero señala que es imprescindible que se instituyan mecanismos de cooperación entre los organismos de control. Es inaceptable, dice la Asamblea, que las actividades que afectan a varios países escapen del control de los órganos de supervisión porque el servicio de inteligencia de cada país invoca la necesidad de proteger su futura cooperación con sus homólogos extranjeros para no informar a los mencionados organismos ${ }^{22}$.

Los organismos judiciales habían alegado ante la Corte Costituzionale que las informaciones declaradas secretas no podían ser cubiertas por el secreto de Estado porque eran informaciones relativas a actividades ajenas a la función institucional del servicio pero la Corte Costituzionale rechazó tal argumento. En nuestro país, la respuesta a esta cuestión por parte de la jurisdicción ha sido muy diferente.

La Audiencia Provincial de Madrid en su Sentencia 155/2002, de 21 de enero, en la que se juzgaba a D. José Barrionuevo, D. José Luis Corcuera, D. Rafael Vera, D. Julián Sancristóbal y tres personas más por la presunta malversación de caudales públicos sirviéndose para ello de los fondos reservados señaló, en el fundamento jurídico cuarto, que surgía un problema de interpretación sobre si el acuerdo «relativo a la clasificación de la organización, medios, procedimientos y fuentes de los servicios de información se extendía a la forma en que se emplean los fondos públicos destinados en un principio gastos reservados cuando no son el medio de pago de actividades reservadas sino, presuntamente, el objeto material de un delito de malversación. Pues bien, en este caso ha de pensarse que la Administración actúa dentro de la legalidad y que no ha declarado incluido en materia clasificada aquello que, por su naturaleza (art. 1 de la ley) no debe serlo, y que no lo ha hecho porque el conocimiento de los hechos no pone en riesgo la Seguridad del Estado ni compromete intereses fundamentales de la nación (y, más bien al contrario, lo que perjudica la Seguridad del Estado

21 Resolución 1838 (2011) de la Asamblea Parlamentaria del Consejo de Europa.

22 En esta línea Salvi señala que en el caso Abu Omar la Corte debería haber declarado que el secreto se había opuesto indebidamente porque no se trataba de tutelar en líneas generales la organización interna del servicio de inteligencia y sus relaciones con servicios extranjeros, sino conductas específicas dirigidas al secuestro y sometimiento a tortura de un ser humano. Vid. SALVI, Giovanni: «La Corte...» p. 32. 
y compromete los intereses nacionales es la corrupción de las Autoridades y funcionarios públicos, sobre todo si cifra su impunidad en un pretendido secreto)». Con base en tal argumento la Audiencia Provincial incorporó a la causa la información relativa al uso dado a los fondos reservados por los recurrentes sin pedir su previa desclasificación al Gobierno.

La sentencia fue recurrida ante el Tribunal Supremo porque entendían los recurrentes que se había vulnerado su derecho a la tutela judicial efectiva con proscripción de indefensión y a un proceso con todas las garantías del artículo 24.1 y 2 de la Constitución, además del principio de legalidad del artículo 25, por inobservancia de la condición objetiva de procedibilidad consistente en la previa desclasificación de la materia relativa al uso y destino de los fondos reservados, dado su carácter secreto. El Supremo rechazó la alegación y señaló que era impensable entender que la Ley de Secretos Oficiales hubiera querido «proteger y ocultar los delitos integrados por la desviación de estos fondos a fines diferentes a los constitucional y legalmente asignados, aplicándolos al propio enriquecimiento y creando, de esa guisa, injustificados espacios de impunidad». La Ley de Secretos Oficiales y normas complementarias deben ser interpretadas conforme a los principios constitucionales. «Si los gastos reservados, lo son por estar destinados a una finalidad concreta, apartados de esa finalidad, queda sin justificación la protección especial dispensada» (fundamento jurídico tercero de la Sentencia del Tribunal Supremo, Sala de lo Penal, núm. 1074/2004 de 18 de octubre). Como se puede observar esta interpretación es muy diferente a la que realiza la Corte Costituzionale italiana en la sentencia 40/2012 23 .

No es éste el único caso que se ha resuelto en este sentido. En el caso de las escuchas ilegales del CESID a personas relevantes de la vida española, la Audiencia Provincial de Madrid condenó a Juan Alberto Perote a cuatro meses y un día de arresto mayor e inhabilitación absoluta por seis años y un día. El condenado interpuso recurso de casación ante el Tribunal Supremo. Entendía que la Audiencia Provincial, al haber dado validez a la declaración del Director del CESID, había vulnerado su derecho a la tutela judicial y a un proceso con todas las garantías. Según el recurrente, los primeros datos sobre la actividad del Gabinete de escuchas del CESID, donde se habían llevado a cabo las interceptaciones telefónicas, sobre su modo de funcionamiento, las identidades del personal a su servicio, los aparatos de que disponía y sus responsables aparecieron por primera vez en dicha declaración del Director del CESID, y afectarían a materias clasificadas de acuerdo con la Resolución del Consejo de Ministros de 28 de noviembre de 1986. Esta resolución declara clasificadas la estructura, organización, medios y procedimientos operativos específicos de los servicios de información, así como sus fuentes y cuantas informaciones o datos puedan revelarlas y los destinos de personal de carácter especial. El recurrente sostenía que para poder utilizar la informa-

23 La Sentencia del Tribunal Supremo fue recurrida a su vez ante el Tribunal Constitucional. Éste, en su sentencia 126/2011, de 18 de julio, declaró que el problema era un problema de interpretación de la ley y que la interpretación y aplicación de la ley corresponde a los tribunales ordinarios. En tanto la interpretación de la ley que se había hecho por los tribunales ordinarios no era irrazonable o arbitraria no podía declararse la existencia de una violación de los derechos del recurrente. 
ción como elemento de investigación y luego de prueba tenía que haberse pedido la desclasificación al Gobierno.

En su Auto núm. 921/2006 el Tribunal Supremo inadmite el recurso de casación. El Tribunal Supremo alega que en ocasiones es preciso sacrificar algunos derechos o aspectos parciales de los mismos para garantizar la propia supervivencia del sistema democrático o incluso de esos derechos individuales. Sin embargo, la existencia de una finalidad legítima no puede llevar a crear espacios de impunidad cuando en la utilización de esos medios o con abuso de los mismos se cometan delitos. La Constitución — dice el Tribunal Supremo - establece en su artículo 9 que los poderes públicos están sujetos a la Constitución y al resto del ordenamiento jurídico, lo que implica que aquellas funciones de inteligencia también lo están. Las funciones que se le atribuyen al CESID (ahora CNI) están orientadas a proteger la seguridad y defensa del Estado «de manera que no es posible sostener que cualquier actuación que pudiera llevar a cabo cualquier funcionario del Centro fuera a quedar automáticamente protegida por la declaración genérica de materia clasificada a que antes se hizo referencia. Por el contrario, ha de entenderse que quedarían excluidas aquellas que claramente excedieran de esas funciones...». En su declaración, el Director del CESID había confirmado la existencia de escuchas de conversaciones privadas sin autorización judicial y la identificación de la persona responsable de la Unidad en la que tales comunicaciones eran interceptadas. Para el Tribunal Supremo en la declaración sólo se reveló información concerniente a la conducta que se consideró delictiva y no se afectó a la seguridad y defensa del Estado por lo que dicha información no merecería la consideración de clasificada; los otros aspectos del funcionamiento interno del centro, como la identidad y demás datos de las personas que prestaban en él sus funciones, carecería de interés para la causa, defiende el Tribunal Supremo, y podría prescindirse de ello sin que supusiera una alteración del fallo de la sentencia impugnada (fundamento jurídico primero). Como se puede observar la posición de nuestro Tribunal Supremo es muy distinta a la de la Corte Costituzionale. A nuestro parecer es más acorde con los postulados del Estado de Derecho, aunque entraña sus peligros el que cada juez se convierta en juez del secreto y decida lo que no está cubierto por el mismo por escapar claramente a las funciones del servicio de inteligencia.

Por último, cabe hacer referencia al papel preponderante que la Corte Costituzionale otorga al Parlamento en el control de los secretos de Estado. Sobre esto podemos decir que el Parlamento ciertamente puede controlar la invocación del Secreto de Estado, realizando un control político muy pertinente dado el amplio margen de apreciación que tiene el Ejecutivo en este ámbito, pero no servir de sustituto al control jurisdiccional. En el Parlamento los intereses que se defienden son esencialmente políticos y no siguen la misma lógica del control judicial, la mayoría, que apoya al Gobierno en los sistemas parlamentarios, es la que tiene la última palabra ${ }^{24}$.

*** $*$

24 Salvi denuncia cómo en numerosas ocasiones el Parlamento, sometido a presiones externas, no ha sabido responder adecuadamente, por ejemplo en los Estados Unidos, y ha tenido que ser el Tribunal Supremo el que años después reparara la situación (por ejemplo, tras el 11-S). Vid. SALVI, Giovanni: «La Corte...» p. 24. 
Title:

ABSTRACT: The Italian Constitutional Court in its Judgments 106/2009 and 40/2012 had to define its fole in the oversight of official secrets. In previous judgments the Italian Constitutional Court had pronounced itself upon the role of the ordinary courts on this field but not upon his own role. In the judgments 106/2009 and 40/2012 the Italian Constitutional Court also deals will the question of the collision between the right to denfece and the need to protect national security. It gives an entirely new solution to the problem. As to the oversight of official secrets, the Italian Constitutional Court is quite deferential towards the Executive.

RESUMEN: La Corte Costituzionale italiana, en las sentencias 106/2009, de 8 de abril (sobre el programa de extraordinary renditions) y 40/2012, de 29 de febrero, se enfrenta por primera vez a la cuestión de cuál deba ser su papel en la fiscalización de los secretos de Estado. Hasta ese momento, la Corte Costituzionale se había pronunciado únicamente sobre el control de los secretos de Estado por los jueces y tribunales ordinarios. La Corte aborda también en estas sentencias el problema de la colisión entre el derecho de defensa y la necesidad de protección de la seguridad del Estado y proporciona una solución novedosa a la cuestión. En relación con la fiscalización de los secretos de Estado, la Corte se muestra, en nuestra opinión, demasiado deferente hacia el Ejecutivo.

KeYwords: Official secrets. Italian Constitutional Court. Right to defence.

Palabras Clave: Secreto de Estado. Corte Costituzionale italiana. Derecho de defensa.

FECHA DE RECEPCIÓN:14.12.2012 FECHA DE ACEPTACión: 12.02.2013. 

TRIBUNAL CONSTITUCIONAL 
